\title{
Time to revisit the orphan drug law
}

\author{
Silvio Garattini
}

Received: 29 July 2011 / Accepted: 31 July 2011 /Published online: 13 August 2011

(C) Springer-Verlag 2011

More than 10 years have been passed since the European Parliament approved a law to encourage pharmaceutical companies to develop drugs for approximately 7,000 rare diseases awaiting a therapy. Several papers published in the meantime have evaluated the outcome of the law [1-3]. In all, 63 drugs have been made available on the market for 73 indications. The largest category $(n=26)$ concerns rare cancers. We have already discussed the poor quality of preclinical development and a number of pitfalls as regards dose-finding, the duration of treatment, and the use of surrogate end-points not always corresponding to therapeutic efficacy $[1,2]$. It may therefore now be time to review the law at least from two main perspectives: the definition of rare diseases and the costs of orphan drugs.

As far as the definition is concerned, it is proposed to lower the prevalence threshold to one-tenth of the present limit, from $5 / 10,000$ to $5 / 100,000$. This is partly justified by the larger population of the EU, as it has grown from the previous 15 Member States to the present 27, reaching a total of about 500 million people. This means that there will be up to 25,000 people in the EU with any disease considered "rare" according to the present proposal, enough to justify a reasonable market. We must not forget that a valid orphan drug will find additional markets outside the EU.

In terms of expenditures, the average cost of a daily defined dose (DDD) of orphan drugs in Italy is about $€ 97$, though with wide variations. This was calculated by dividing the yearly cost of orphan drugs $(€ 661,709,750)$ in Italy by the number of DDD/year $(6,839,423)$. If we

\section{S. Garattini $(\bowtie)$}

Mario Negri Institute for Pharmacological Research,

Via Giuseppe La Masa 19,

Milan, Italy

e-mail: silvio.garattini@marionegri.it multiply the cost of 1 year of treatment by the upper limit of a rare disease $(25,000$ people in Europe) the total gross income will be about $€ 885$ million. Although the net income will be about half this amount once the ex-factory price is applied, even a fraction of it would be satisfactory. Considering that the exclusivity will run for 10 years, there is no doubt that a pharmaceutical company will amply recover the expenses of developing an orphan drug [4]. It would be advisable, however, to put a ceiling on the public expenditure for orphan drugs to maintain the privilege of 10 years' exclusivity. This would avoid situations such as was the case for imatinib, which has obtained 6 indications with a yearly income amounting to $€ 145$ million only in Italy.

These changes will not affect the really rare diseases, those with a prevalence, for instance, of $1 / 1,000,000$ inhabitants, for which a special European fund will have to be set up as an incentive for the development of the necessary orphan drugs.

Disclosure I declare I have no conflict of interests.

\section{References}

1. Joppi R, Bertele' V, Garattini S (2006) Orphan drug development is progressing too slowly. Br J Clin Pharmacol 61:355-360

2. Joppi R, Bertele' V, Garattini S (2009) Orphan drug development is not taking off. Br J Clin Pharmacol 67:494-502

3. The Committee for Orphan Medicinal Products and the European Medicines Agency Scientific Secretariat (2011) European regulation on orphan medicinal products: 10 years of experience and future perspectives. Nat Rev Drug Discov 10:341-349

4. Roos JC, Hyry HI, Cox TM (2010) Orphan drug pricing may warrant a competition law investigation. BMJ 341:C6471 